\title{
Mulemba
}

Revista Angolana de Ciências Sociais

5 (10) | 2015

Angola 40 anos de independência: memória, identidades, cidadania e desenvolvimento

\section{A lógica da distinção em Pierre Bourdieu, vista através de uma obra excepcional}

\section{Cesaltina Abreu}

\author{
(2) OpenEdition \\ Journals \\ Edição electrónica \\ URL: http://journals.openedition.org/mulemba/2195 \\ DOI: 10.4000/mulemba.2195 \\ ISSN: 2520-0305 \\ Editora \\ Edições Pedago

\section{Edição impressa} \\ Data de publição: 1 novembro 2015 \\ Paginação: 841-964 \\ ISSN: 2182-6471 \\ Refêrencia eletrónica \\ Cesaltina Abreu, «A lógica da distinção em Pierre Bourdieu, vista através de uma obra excepcional», \\ Mulemba [Online], 5 (10) | 2015, posto online no dia 13 outubro 2018, consultado o 26 janeiro 2021. \\ URL: http://journals.openedition.org/mulemba/2195; DOI: https://doi.org/ERREUR PDO dans / \\ localdata/www-bin/Core/Core/Db/Db.class.php L.34 : SQLSTATE[HY000] [2006] MySQL server has \\ gone away
}




\title{
A lógica da distinção em Pierre Bourdieu, vista através de uma obra excepcional*
}

\author{
Cesaltina Abreu**
}

\section{O Autor}

O campo de reflexão privilegiado de Pierre Bourdieu é a sociologia das classes dominantes e os mecanismos de dominação e reprodução resultantes das relações de poder entre as classes sociais; nas suas obras, manifesta constante preocupação com as relações funcionais de operação da sociedade, dentre os quais, um dos requisitos fundamentais: a legitimação da relação de dominação.

A teoria dos campos de produção simbólica procura mostrar que as relações de força entre os agentes sociais apresenta-se segundo a forma transfigurada de relações de sentido. A violência simbólica, outro tema central na sua obra, não é um puro e simples instrumento ao serviço da classe dominante, mas algo que se exerce através do jogo entre os agentes sociais.

Um dos pontos originais da sua obra reside na pretensão de resolver as contradições - por ele designadas de falsas antinomias -, da tradição sociológica: interpretação e explicação, estrutura e história, liberdade e determinismo, comunidade e sociedade, objec-

* Cf. Pierre Bourdieu, La Distinction. Critique sociale du jugement. Paris, Les Éditions de Minuit, 1979, 670p. [«Le sens commun»].

** Socióloga. Professora Auxiliar e Chefe do Departamento de Sociologia da Faculdade de Ciências Sociais (FCS) da Universidade Agostinho Neto (UAN). 
tivismo e subjectivismo, através da criação de articulações entre os níveis micro e macro, e agência e estrutura para superar as perspectivas dicotómicas. Ao formular a teoria da prática, ele não pretende negar o objectivismo nem o subjectivismo, apenas superá-los, articulando os aportes teóricos de ambos.

Defendia a possibilidade e a necessidade do intelectual crítico, pois para ele não haverá democracia efectiva sem um verdadeiro contra-poder crítico. Um dos principais alvos de crítica de Bourdieu, nos últimos anos de vida, foram os meios de comunicação que estariam, segundo ele, cada vez mais submetidos a uma lógica comercial inimiga da palavra, da verdade e dos significados reais da vida; era um crítico feroz do lixo cultural produzido pelos media contemporâneos. «Esse poder simbólico que, na grande maioria das sociedades, emana do poder político ou económico, hoje está concentrado nas mãos das mesmas pessoas que detêm os grandes grupos de comunicação, controlando assim o conjunto de instrumentos de produção e de difusão dos bens culturais». ${ }^{\mathbf{1}}$

Um dos seus importantes legados é a convocação aos intelectuais para abandonarem a «cidade dos sábios» e passarem a enfrentar o som e a fúria do mundo; era preciso, dizia, tirar o saber para fora da «cidade dos sábios» e colocá-lo ao serviço das lutas sociais contra o neo-liberalismo. ${ }^{2}$

\section{A obra}

Este trabalho tem em vista sintetizar algumas das principais ideias e estruturas analíticas apresentadas pelo Autor nos diversos capítulos do livro La Distinction.

No capítulo dedicado ao espaço social e suas transformações, são centrais as noções de classe social e de espaço social; a primeira envolve a noção de espaço social, a distinção entre «classes reais» e «classes teóricas», bem como o papel central do trabalho na mobilização política. A ideia de «espaço social» corresponde à sociedade:

1 Questions aux vrais maîtres de mon temp - 11 Octobre 1999 à Paris, devant le Conseil International du Musée de la Télévision et de la Radio (MTR).

2 Marc Weissheimer, "O legado crítico de Pierre Bourdieu», Revista Espaço Acadêmico (Porto Alegre), Ano I, n. ${ }^{\circ}$ 10, Março de 2002, 2p., disponível em <http://www.espacoacademico.com.br> 
ele é multidimensional, construído a partir de princípios de diferenciação e constituído de propriedades actuantes, ou seja, as diferentes espécies de capital, distribuídas nos diversos campos do espaço social. A ideia de capital subentende "poder» e encontra-se associada directamente à ideia de probabilidade de ganhos num determinado campo - profissional, cultural, artístico, etc. -, poder ser «objectivado», envolvendo propriedades materiais como posse de bens, ou «incorporado» envolvendo bens simbólicos ou culturais, como prestígio, reputação, diploma.

A posição de cada agente ou grupo de agentes no espaço social pode ser definida pela posição que ocupa em cada um dos diferentes campos em que actua, o que depende da relação das forças em cada um deles, de acordo com a lógica típica de cada campo. Assim, a «condição» - as propriedades intrínsecas - e a «posição» - as propriedades relacionais - de cada agente ou grupo de agentes no espaço social multidimensional, depende do volume global e da composição do capital que tais agentes possuem. Os agentes não se deslocam no espaço social ao acaso, não só porque as forças que estruturam tal espaço se opõem a eles, mas também porque eles (agentes) lhes opõem as suas propriedades que podem estar incorporadas sob a forma de disposições, ou objectivadas sob a forma de bens ou títulos. A um dado volume de capital herdado, corresponde um leque de trajectórias com probabilidades bastante próximas, conduzindo a posições mais ou menos equivalentes, constituindo, assim, o campo de possibilidades que se oferece a cada agente. A passagem de uma trajectória a outra depende, na maior parte das vezes, de acontecimentos colectivos ou individuais, atribuídos ao acaso, ainda que dependam estatisticamente da posição e das disposições daqueles a quem atingem. Ou seja, a posição e a trajectória de um agente não são independentes estatisticamente, porque existe uma correlacção muito forte entre as posições sociais e as disposições dos agentes.

Segundo Bourdieu, a homogeneidade das disposições associadas a uma dada posição e respectivo ajustamento, resulta de mecanismos que orientam os indivíduos para tais posições por «vocação» - porque se sentem adequados ao posto - ou por «cooptação» fundada numa harmonia imediata das disposições. A correlacção entre origem social e uma prática resulta de dois efeitos: o «efeito de inculcação» exercido pela família e pelas condições originais de existência, e o «efeito da trajectória social» da experiência sobre 
as disposições e as opiniões; é este efeito que faz a diferença entre agentes sujeitos ao mesmo tipo de inculcação, por exemplo, irmãos que optam por trajectórias bastante diferentes.

Nesta fase da análise, o Autor faz uma reflexão interessante como contribuição para a explicação da emergência de fanatismos ou radicalismos: os agentes ou grupos de agentes em declínio refugiamse numa reinvenção constante do passado e da tradição, porque nada esperam do futuro a não ser o retorno a uma velha ordem social na qual poderiam voltar a restaurar o seu próprio «ser social». Outra reflexão interessante é a relativa ao envelhecimento social enquanto processo de ajustamento à realidade através do abandono dos sonhos e aspirações e a instalação de um sentimento de «quase contentamento», uma aceitação da conformidade que encontra respaldo numa «cumplicidade» colectiva.

A lógica da distinção aplica-se a um sistema de inclusão e de exclusão: as relações entre os aspectos económicos e simbólicos envolvem um processo apresentado como uma «estilização da vida», no qual os sistemas simbólicos - estruturas de homologias e de oposições ou de desvios diferenciais - realizam a função social de associação ou de dissociação, manifestando assim os desvios diferenciais que definem a estrutura de uma sociedade enquanto sistema de significações.

As diferenças económicas são ampliadas pelas distinções simbólicas no consumo dos bens, ou seja, a transformação de bens de consumo em signos, privilegiando a maneira ou a forma da acção ou do objecto em vez da sua função. Isso acontece frequentemente com o vestuário, a linguagem e as «boas maneiras»: são traços distintivos que simbolizam a posição de um agente ou grupo de agentes na estrutura social, embora apareçam como propriedades da pessoa, como uma natureza, embora não passem de uma natureza culturalmente cultivada. As diferenças primárias - relativas ao volume 844 global de capital enquanto conjunto de recursos e poderes efectivamente utilizáveis e que diferenciam as grandes classes de condições existentes -, normalmente dissimulam as diferenças secundárias, que são definidas pelas distintas estruturas patrimoniais, ou seja, as diferentes formas de distribuição do capital global de cada agente pelas diversas espécies de capital que possui.

As noções de «classe teórica» - agrupamento fictício construído pelo Autor como princípio de classificação explicativo - e de «classe real» - os grupos reais, mobilizados por objectivos comuns, tal 
como existem na sociedade -, são muito importantes para delimitar os dois tempos de análise de Bourdieu: numa primeira etapa, ele parte da construção de «classes teóricas» para classificar os grupos sociais, identificando a posição dos agentes no espaço social teoricamente construído, relacionando volume global de capital e sua composição com a trajectória social dos indivíduos, em classificações com pretensão de objectividade. Numa outra etapa, ele procura incorporar as formas de luta pela classificação, protagonizadas pelos grupos, que se dão na vida real, através das quais buscam modificar a sua posição nas classificações objectivas ou os próprios princípios segundo os quais essas classificações são produzidas.

«A reconversão do capital que se possui numa outra espécie de capital, mais acessível, mais rentável e/ou mais legítima, num dado estado do sistema de instrumentos de reprodução, tende a determinar uma transformação da estrutura patrimonial, e traduzem-se em deslocamentos no espaço social [...] associados a uma mudança de condição» (La Distinction, p. 145).

Estes deslocamentos tanto podem ser «verticais», ascendentes ou descendentes, mas, em geral, dentro do mesmo campo, como «transversais», implicando a passagem de um campo a outro; enquanto os primeiros e mais frequentes, implicam uma variação no volume de capital dominante na estrutura patrimonial, os segundos implicam a reconversão de uma espécie de capital em outra, e portanto, uma transformação na estrutura patrimonial.

Das estratégias de reconversão, uma das mais comuns é a transformação do capital económico em capital escolar. Para Bourdieu, a educação reproduz o capital cultural que se traz da família, reproduzindo a situação de classe não mais via herança de capital económico, mas através do capital social e cultural. Segundo ele, a ideologia do sistema educacional assenta no seguinte: o sucesso na carreira é apresentado como dote individual e não via capital cultural adquirido pela família. Entretanto, a distância entre as aspirações que o sistema de ensino produz e as oportunidades que ele realmente oferece, afecta conjuntos de gerações escolares, de acordo com os factos ocorridos em cada época, e gera revolta em relação ao sistema de ensino; segundo o autor, as actuais gerações, que retiram do valor dos seus títulos menos do que as anteriores retiraram, «[...] desenvolvem uma espécie de humor anti-institucional [...] uma 
espécie de denúncia dos pressupostos tacitamente assumidos de ordem social [...]» (cf. La Distinction, p. 164).

A contradição específica deste modo de reprodução (escolar) que reside na oposição entre os interesses da classe que estatisticamente a escola serve, e os interesses dos membros dessa classe que ela sacrifica, está na origem das mais importantes transformações das estruturas sociais, uma vez que ela serve de suporte a estratégias para escapar à desclassificação provocada pela desvalorização dos títulos escolares, retomando a trajectória de classe, e para prolongar o curso interrompido de uma trajectória. No primeiro caso, as opções que se colocam aos agentes são, segundo o Autor, a escolha de novas profissões mais ajustadas às suas pretensões ou a indução a uma redefinição das carreiras às quais os seus títulos lhes dão acesso, o que geralmente implica, também, a transformação do posto de trabalho através de uma nova divisão do trabalho.

O entendimento desta problemática envolve o conceito de capital social tal como ele o entende. É sua a primeira análise contemporânea sistematizada de capital social, definindo-o como «o agregado das fontes actuais ou potenciais que estão ligadas à posse de uma rede durável de relações mais ou menos institucionalizadas de mútuo conhecimento ou reconhecimento» (The forms of capital, 1985, p. 248). O seu tratamento do conceito é instrumental, focalizado nos benefícios acumulados para o indivíduo em virtude da participação em grupos e na construção deliberada da sociabilidade com o propósito de criar este recurso. Ele afirmou que «os benefícios que advêm da afiliação num grupo são a base de solidariedade que os torna possíveis» (The forms of capital, 1985, p. 249). As redes sociais não são um dado natural e devem ser construídas através de estratégias de investimento orientadas para a institucionalização das relações do grupo, usadas como uma fonte segura de outros benefícios.

A definição de Bourdieu torna claro que o capital social é passível de decomposição em dois elementos: $1^{0}$ - a relação social que permite aos indivíduos terem acesso a recursos em posse dos seus associados e $2 .^{\circ}$ - o montante e a qualidade desses recursos. A ênfase de Bourdieu reside na fungibilidade das diferentes formas de capital e na sua redução final a capital económico, definido como trabalho humano acumulado. Por esta razão, através do capital social, os agentes podem ganhar acesso directo a recursos económicos (empréstimos subsidiados, pequenos investimentos, mercados 
protegidos); podem aumentar o seu capital cultural através de contactos com especialistas ou indivíduos mais refinados (por exemplo, capital cultural incorporado) ou, alternativamente, eles podem afiliar-se a instituições que conferem credenciais valorizadas (por exemplo, capital cultural institucionalizado). Por outro lado, a aquisição de capital social requer um investimento deliberado, tanto em recursos económicos quanto em recursos culturais.

Segundo o Autor, a dialética da desclassificação e da reclassificação encontra-se no princípio de todos os tipos de processos sociais e implica e impõe estratégias colectivas grupais, tornando-se inacessíveis a outros grupos que os precedem ou que os seguem, ou seja, estabelece-se uma ordem de sucessões separando os grupos concorrentes por diferenças que se situam numa ordem do tempo. Assim, a ordem social num dado momento tem uma conotação temporal, devido ao processo de transformação dos objectivos, dos sentidos, e das propriedades substanciais. Para ele, a luta de concorrência eterniza não as condições diferentes, mas antes a diferença de condições.

Neste sentido, a reprodução da estrutura social pode realizar-se na, e através da, luta de concorrência, conduzindo a uma simples translação da estrutura de distribuições por acções e reacções, que apenas se totalizam estatisticamente pelos efeitos externos que as acções de uns exercem sobre as acções de outros e, objectivamente, fora do controlo colectivo ou individual e, na maior parte das vezes, contra os interesses individuais e colectivos dos agentes, provocando o que designa de «efeito de debandada», levando cada agente a reagir isoladamente ao efeito de inúmeras reacções de outros agentes, o que reduz a classe ao estado de «massa dominada», pelo seu próprio número e pela sua própria massa.

\section{O habitus e o espaço dos estilos de vida}

A esfera simbólica e cultural é constituída por bens simbólicos e culturais; ela está intimamente relacionada com a estrutura social, constituída pelas relações de força e de poder entre classes. Por seu lado, a estrutura social «determina» o habitus (sistema de disposições internalizadas que dá predisposições para a acção e comanda as práticas adequadas à estrutura social).

Esta ideia de habitus, fortemente conectada com a ideia de reprodução, tem a sua base de sustentação na intuição de que a revolução 
não é a norma. Tanto a ideia de habitus quanto a ideia de campus não são teóricas, mas chaves analíticas para a interpretação da dinâmica social. A sociedade é hierarquizada, os campus reproduzem essa hierarquia fundamental que estrutura as outras hierarquias sociais. A posição de uma pessoa num campus da estrutura social é fruto de uma trajectória que determina as possibilidades de fruição económica, estética, etc.; por sua vez, essa trajectória é determinada pelo volume de capital económico e pela composição do total de capital de que essa pessoa é dotada. Nesse sentido, o habitus, representando a interconexão de vários elementos de socialização e o campus, é um espaço de conflito.

Os bens simbólicos distinguem-se dos bens materiais na medida em que eles só podem ser apropriados por indivíduos que têm um sistema de apreciação ou de códigos para a interpretação e valorização. O capital cultural é o conjunto de posições cultivadas que formam o entendimento dos bens simbólicos e culturais. Este conceito de capital cultural está muito próximo da ideia de hábitos de classe diferenciados.

O habitus é, simultaneamente, um princípio gerador de práticas objectivamente classificáveis e um sistema de classificação dessas práticas, um meio de diferenciar e apreciar essas práticas e esses produtos (o gosto); é na relação entre estas duas capacidades que se define o habitus e se constitui o mundo social representado, o espaço dos estilos de vida. É o habitus que opera a atribuição de sentido às práticas, aos produtos e aos julgamentos classificáveis, construindo um sistema de signos distintivos. O habitus realiza funções essenciais à aprendizagem, tornando as práticas de um agente ou grupo de agentes não só sistemáticas, mas também sistematicamente diferentes das práticas de outro estilo de vida. As práticas que originam os diferentes habitus apresentam-se como configurações sistemáticas de propriedades que exprimem as diferenças objectivamente inscritas nas condições de existência, sob a forma de sistemas de desvios diferenciais que, percebidos pelos agentes dotados dos esquemas de percepção e apreciação necessários para os notarem, interpretarem e avaliarem, funcionam como estilos de vida.

Condições de existência diferentes produzem habitus diferentes; cada condição é definida pelas propriedades intrínsecas e pelas propriedades relacionais; por isso, o sistema de condições é, igualmente, um sistema de diferenças. Daí que a identidade social se defina e se afirme pela diferença. Os estilos de vida são produtos sistemáticos 
dos habitus percebidos pelos sistemas de signos, socialmente qualificados como «distintos» ou como «vulgares», estes menos sofisticados, mais generalizados e acessíveis.

O «gosto» é a propensão à apropriação por uma determinada classe de objectos ou práticas e constitui-se, desta forma, em gerador de estilo de vida. Ele é um operador prático da transmutação das coisas em signos distintos e distintivos, de distribuições contínuas em oposições descontínuas; ele permite o acesso das diferenças inscritas na ordem física à ordem simbólica das distinções significantes e transforma práticas objectivamente classificáveis em práticas classificadoras, ou seja, em expressão simbólica da posição de classe. E faz isso porque percebe as práticas nas suas relações mútuas e em função de esquemas sociais de classificação. Os sistemas de classificação operam continuamente a transfiguração das necessidades em estratégias, dos constrangimentos em preferências, e engendra o conjunto de escolhas do estilo de vida, procurando ajustar essas escolhas às condições em que foi produzido: após uma mudança de posição social, as condições nas quais o habitus foi produzido não coincidem com as condições nas quais ele funciona, dando espaço à manifestação da eficácia própria, o gosto (de necessidade ou de luxo).

Os estilos de vida distintos estimulam consumos distintos, da mesma forma que os estilos de vida vulgares estão associados a consumos vulgares. As práticas pretensiosas resultam da discordância entre a ambição e as possibilidades. Mais pela mediação dos meios de apropriação de que dispõem, exclusiva ou principalmente culturais, por um lado, e quase sempre económicos, por outro, e as diferentes formas de relação com as obras de arte que daí resultam, as distintas fracções da classe dominante orientam-se para práticas culturais tão diferentes no seu estilo e no seu objecto - por vezes mesmo antagónicas -, que levam a esquecer que são variantes de uma mesma relação fundamental com a necessidade e com os que lhe estão submetidos, e que elas têm em comum a busca pela apropriação exclusiva dos bens culturais legítimos e os lucros da distinção que esta proporciona.

Os gostos de luxo são próprios de indivíduos que são produto de condições materiais de existência definidos como distância da necessidade, liberdades e facilidades decorrentes da posse de um tipo de capital, em geral associado ao capital económico. Os gostos de necessidade são típicos daqueles que experimentam no seu 
ajustamento as necessidades de que são produto. Considerando a ideia de gosto tipicamente burguês (uma vez que supõe absoluta liberdade de escolha), Bourdieu afirma que o verdadeiro princípio das preferências é o gosto como necessidade feita virtude, e o verdadeiro princípio de diferenciação reside na oposição entre «gostos de luxo» e «gostos de necessidade». Os gostos populares por alimentos mais nutritivos e mais económicos deduzem-se da necessidade de reproduzir a força de trabalho ao menor custo possível. As coincidências que ocorrem em posições extremas do espaço social são interpretadas como «luxo electivo» por uns, e como «efeitos de privação», por outros.

$\mathrm{Na}$ sua análise, o estilo de vida denuncia de imediato quem pertence aos estratos sociais mais carentes, estigmatizados como aqueles que «não sabem viver», os que «comem e bebem demais» e se «comportam sem maneiras», «se vestem sem cuidado», «não cuidam do corpo nem da mente», etc., numa série de qualificações que se constituem como um «racismo de classe». A esta «moral da vida boa», que se reflecte também na forma como se relacionam com familiares e amigos - com um certo licenciamento de comportamentos domésticos, que reflecte a vontade de não impôr controlos nem restrições no único/último reduto de liberdade que as pessoas têm, estando nos demais sempre sujeitas à necessidade -, as classes dominantes contrapõem a «nova ética da sobriedade» - no ambiente doméstico burguês prevalece a preocupação da introdução e reprodução das regras, como um hábito de ordem, que reflecte a sua relação com o mundo social -, alcança todos os aspectos da vida: da alimentação às relações na família e desta com o seu entorno, da maneira de vestir e de se apresentar no trabalho ou em público, às estruturas de consumo que lhes estão relacionadas. Esta diferença de estilos que na verdade opõe o «ser» ao «parecer», a «substância» à «forma», reflecte-se nos lugares públicos frequentados pelos distintos grupos sociais: dos cafés/restaurantes do pequeno burguês, com suas mesas individuais definindo territórios privados e apropriados, ao café popular em que todos se integram.

As estruturas de consumo são constituídas diferentemente: na classe dominante os principais itens são a alimentação, a cultura e as despesas de apresentação e de representação, assumindo formas relacionadas com as distintas formas de capital que os grupos que a compõem, possuem; por exemplo, enquanto comerciantes e industriais apresentam consumos alimentares mais elevados, despesas 
culturais muito reduzidas e despesas medianas com a representação e apresentação, os professores gastam mais em actividades culturais.

Estas diferenças distintivas entre estilos de vida reflectem-se não só em matéria de gostos alimentares e no modo de cozinhar, apresentar e servir os alimentos, mas também na divisão sexual do trabalho. Os alimentos mais leves, congelados ou frescos, servidos em saladas, por exemplo, estão relacionados com uma estrutura familiar em que a mulher tem outras actividades profissionais, em geral fora de casa. Numa época em que a cultura do corpo é a objectivação mais irrecusável do gosto de classe - na medida em que existe um mercado de trabalho que valoriza a estética no meio profissional, transformando a beleza em mercadoria valorizada como um capital (neste caso, corporal), os gostos alimentares reflectem preferências relacionadas com a estética corporal (forma), ou com a ideia de força, em qualquer dos casos introduzindo um viés de género que acaba conduzindo à criação de identidades masculinas e femininas, diferentes no porte, na atitude, nas preferências e nos comportamentos; ou seja, para além de portador de signos, o corpo também é produtor de signos ou gestos relacionados com a masculinidade e a feminilidade.

Em relação estreita com a cultura, os signos do corpo adquirem uma feição que não só os faz parecerem naturais, como os remete a grupos sociais específicos dessa cultura, desenhando assim um espaço dos corpos de classe, que tende a reproduzir a lógica específica da estrutura do espaço social. As marcas cosméticas viram marcas sociais, recebendo sentido e valor da sua posição no sistema de signos distintivos, homólogo do sistema de posições sociais. A representação social do corpo, através da qual cada agente elabora a sua apresentação subjectiva, obtém-se pela aplicação de um sistema de classificação social cujo princípio é o mesmo dos produtos sociais ao qual se aplica.

A construção dos espaços dos estilos de vida requer o estabelecimento da forma genérica de habitus, para cada classe ou fracção de classe, que traduza as necessidades e facilidades características dessa classe e determine «como» as distribuições do habitus se especificam para cada um dos grandes domínios da prática: desporto, música, política, etc. Cada universo apresenta-se como um conjunto de escolhas preparadas de possíveis objectivamente instituídos, de tradições, regras, valores, equipamentos, técnicas, símbolos, etc., 
que recebem a sua significação social do sistema que eles constituem e a que devem parte das suas propriedades, num dado momento da sua história.

Pegando no exemplo da prática desportiva, o autor considera que as variações destas práticas segundo as classes dependem das variações na percepção e na apreciação dos ganhos/benefícios, imediatos ou diferidos; ou seja, existe uma relação instrumental do corpo típico da classe com as preferências e escolhas, que também se reflecte na composição das audiências. A explicação da distribuição das práticas desportivas entre as classes passa pelo poder económico, mas também pelos «direitos de entrada» incorporados na tradição familiar e na aprendizagem, na sociabilidade de rigor, o que interdita algumas práticas - como a equitação e o iatismo às classes populares e aos indivíduos em ascensão. A história das práticas desportivas da classe dominante coincide com a evolução das disposições éticas da representação burguesa de ideal humano e, particularmente, da conciliação entre ideais corporais e virtudes intelectuais. Para o Autor, esta oposição entre duas relações com o mundo social resume-se nas duas relações com o mundo natural: por um lado, o gosto pela natureza natural, selvagem; por outro lado, a natureza policiada, balizada, cultivada.

\section{A dinâmica dos campos}

A relação de distinção encontra-se objectivamente inscrita e reactiva-se em cada acto de consumo através dos instrumentos de apropriação económicos e culturais; o objecto de arte é a objectivação de uma relação de distinção, transportando consigo essa distinção aos mais diversos contextos. As criações culturais que admiramos do ponto de vista puramente estético, são percebidas como expressões diferenciadas de certas qualidades sociais. Toda a apropriação de uma obra de arte, que é em si uma relação de distinção realizada, representa também uma relação social e uma relação de distinção.

A apropriação de bens culturais supõe disposições e competências que não se encontram universalmente distribuídas na sociedade. Trata-se de uma apropriação material e simbólica exclusiva, funcionando como capital cultural (objectivado ou incorporado), que assegura um benefício de distinção devido à raridade dos instrumentos necessários à sua apropriação, e um benefício de 
legitimidade a partir da identificação de quem se apropria do objecto apropriado. Aqui reside a diferença entre a cultura legítima das sociedades divididas em classes - produto da dominação predisposta a exprimir e legitimar essa dominação -, e a cultura das sociedades pouco ou nada diferenciadas, onde o acesso aos instrumentos de apropriação da herança cultural é mais ou menos igualmente repartido, não podendo essa cultura funcionar como capital cultural, ou seja, como instrumento de dominação.

O benefício simbólico perseguido pela apropriação material ou simbólica de uma obra de arte mede-se pelo seu valor distintivo, em função da raridade da disposição e da competência, que orienta a sua distribuição entre as classes. O poder distintivo da posse ou do consumo culturais, obras de arte, títulos escolares, etc., tende a diminuir à medida que aumenta o número absoluto daqueles que têm condições de se apropriarem deles; por essa razão, os benefícios da distinção seriam depreciados se o campo de produção de bens culturais, regido pela dialéctica da pretensão e da distinção, não oferecesse continuamente novos bens e novas formas de apropriação de tais bens.

O ajustamento entre a oferta e a procura de bens culturais é resultado da articulação objectiva de duas lógicas relativamente independentes: a dos campos de produção e a dos campos de consumo. A demanda constitui-se nas lutas de concorrência que opõem as diferentes classes, ou fracções de classes, relativamente a tais bens, as quais estão, também, na origem das mudanças de gostos. É esta articulação da oferta e da procura que faz com que os gostos mais variados encontrem condições para a sua realização no universo dos possíveis oferecido por cada um dos campos de produção, enquanto estes encontram as condições da sua constituição e do seu funcionamento na diversidade de gostos que asseguram um mercado para os seus produtos.

Na produção de bens culturais, a relação entre a oferta e a procura reveste-se de uma forma particular: a oferta exerce sempre um efeito de imposição simbólica. Um produto cultural é um gosto constituído e este, por seu lado, um sistema de classificação constituído por condicionamentos associados a uma condição numa determinada posição do espaço das condições diferentes; comanda as relações com o capital objectivado e com o mundo de objectos hierarquizados que contribuem para o explicitar. Os gostos efectivamente realizados dependem do estado do sistema de bens 
oferecidos: qualquer mudança do sistema de bens tem como consequência uma mudança de gosto; pelo contrário, qualquer mudança de gostos resultante da transformação das condições de existência e das disposições correlactivas das condições de existência, determina a transformação do campo de produção, com vantagens para os produtores melhor posicionados para produzir as necessidades correspondentes às novas disposições.

Os produtos são orientados pela lógica da concorrência entre si e pelos interesses específicos das duas posições no campo de produção (ou seja, pelo habitus) a produzirem produtos distintos que vão de encontro aos diferentes interesses culturais dos consumidores, em função das suas condições e respectivas posições de classe; ou seja, a lógica da existência de consumo para todos os gostos não é o produto de uma busca intencional, mas o encontro de dois sistemas de interesses.

O princípio da homologia funcional e estrutural deriva do facto que os distintos campos tendem a organizar-se segundo a mesma lógica: volume do capital específico possuído, o que significa que as oposições entre ricos e pobres, distinção e pretensão, velhos e novos, etc., também são homólogas entre si e homólogas das oposições que organizam o campo das classes sociais em dominadores e dominados e, no seio da classe dominante, entre as suas distintas fracções. É este sentido de homologia entre bens e grupos, que estabelece as bases do acordo entre classes de produtos e classes de consumidores, que define os gostos: escolher segundo os gostos significa ajustar os bens objectivamente relacionados com a sua posição de classe.

A lógica do funcionamento dos campos de produção de bens culturais e as estratégias de distinção que estão na base da sua dinâmica fazem com que os seus produtos funcionem diferencialmente como instrumentos de distinção, primeiramente entre as fracções e, em seguida, entre as classes. Estas funções sociais selectivas independem da intenção dos produtores, pois mesmo sem investimentos intencionais em interesses que não os seus próprios, acabam por endereçar as expectativas de públicos diferenciados em classes. Entre o puro desinteresse e o servilismo cínico há espaço para o estabelecimento objectivo de diversas relações, fora do âmbito da intenção consciente, entre produtores e o público, o que faz com que as práticas e as obras produzidas num campo de produção especializado e relativamente autónomo sejam necessariamente determinadas, e 
que as funções que desempenham nas lutas internas assumam a forma de funções externas que recebem das lutas simbólicas entre as fracções da classe dominante e, mais tarde, entre as classes.

A sinceridade surge nesta discussão enquanto uma das condições da eficácia simbólica; ela apenas se torna possível quando existe um acordo perfeito, imediato, entre as expectativas inscritas na posição ocupada e as disposições do ocupante. Para o Autor ela é o privilégio daqueles que, guiados pelo seu sentido social, encontraram o seu lugar natural no campo de produção. As afinidades electivas mais imediatas parecem depender, em parte, da descodificação inconsciente de traços expressivos (sorriso e linguagem, por exemplo) dos quais apenas tomamos o sentido e o valor quando inseridos no sistema das suas variações de acordo com as classes. O gosto é que harmoniza e aproxima as coisas e as pessoas: a maior prova de afinidade de gostos entre duas pessoas é o gosto que têm uma pela outra.

As lutas pela apropriação dos bens económicos ou culturais são inseparáveis das lutas simbólicas de apropriação dos signos distintivos ou pela conservação, ou subversão, de princípios de classificação das propriedades distintivas. Assim, o espaço dos estilos de vida não é senão um balanço, num dado momento, das lutas simbólicas que visam a imposição do estilo de vida legítimo. A dinâmica do campo no qual os bens culturais se produzem, reproduzem e circulam, causando benefícios de distinção, assenta nas estratégias que são a causa da sua raridade e da sua valorização, e que contribuem para a realização dos seus objectivos pela concorrência que lhes opõem: a distinção ou «a classe», manifestação legítima da classe social, não existe senão através das lutas pela apropriação exclusiva dos signos distintivos que fazem a «distinção natural».

\section{O sentido da distinção}

Partindo dos pressupostos que: $\mathbf{1 .}^{\mathbf{0}}$ - a classe dominante se constitui num espaço relativamente autónomo, cuja estrutura é definida pela distribuição das diferentes espécies de capital entre os seus membros, de forma que cada fracção se caracteriza por uma certa distribuição à qual corresponde, por meio do habitus, um certo estilo de vida; $2 .^{\circ}$ - as distribuições de capital económico e cultural entre tais fracções apresentam estruturas simétricas e inversas, e $3 .^{\circ}$ - as diferentes estruturas patrimoniais estão, conjuntamente 
com a trajectória social, na base do habitus e das escolhas sistemáticas que ele produz em todos os domínios das práticas, deverá ser possível encontrar estas estruturas no espaço dos estilos de vida, ou seja, nos distintos sistemas de propriedades onde se exprimem os diferentes sistemas de disposições.

A partir de uma pesquisa abrangendo 467 pessoas da classe dominante e compreendendo diferentes conjuntos de questões com o objectivo de determinar se as estruturas e os factores explicativos obtidos a partir das respostas variavam em função dos domínios de práticas considerados, e visando, ainda, medir competência legítima, disposição estética, níveis médios de cultura, disposições éticas, entre outros, todas as análises demonstravam uma oposição entre a fracção da classe dominante mais rica em capital cultural e a fracção mais rica em capital económico, enquanto os representantes de profissões liberais se situavam no meio-termo entre os professores de ensino superior e os artistas, de um lado, e os grandes comerciantes e industriais, de outro.

A análise de correspondências permite isolar diferentes conjuntos coerentes de preferências, relacionados com sistemas de disposições distintos e distintivos, definidos tanto pela relação entre si quanto pelas suas relações com as respectivas condições sociais de produção. Segundo o Autor, a análise permite ver que a estrutura organizativa dos indicadores dos diferentes estilos de vida corresponde à estrutura do espaço dos estilos de vida, ou seja, à estrutura de posições sociais.

Considerando não haver diferenças significativas relativamente ao volume global de capital, já que o grupo-alvo é constituído por membros da mesma classe, a posição de cada um deles no espaço determinado por esses factores depende, essencialmente, da estrutura do seu património - do peso relativo do capital económico e do capital cultural que possuem - e da trajectória social, através do modo de aquisição que lhe é correlaccionado. O segundo factor relacionado com a antiguidade de pertencimento à classe dominante, estabelece uma divisão dentro das fracções: por um lado, as de origem burguesa e, por outro lado, as que vêm de outras classes sociais, numa oposição entre membros mais velhos e precedentes de fracções mais antigas e/ou mais ricas em capital económico, e as mais jovens e, em geral, menos ricas em capital económico, oriundas de outras classes sociais (o que foi possível determinar a partir da profissão dos pais). A relação que se estabelece entre a 
posição das fracções no espaço (a antiguidade) e a idade, explicativa de diferenças éticas ou estéticas, opções desportivas ou de vestuário, encontra a sua explicação no aumento do número de «ascendentes», em ordem decrescente das fracções dominantes para as fracções dominadas, ou seja, a sua maior concentração nas fracções inferiores da classe dominante. $\mathrm{O}$ terceiro factor relacionado com o nível médio de cultura, opõe professores e artistas a empresários, comerciantes e industriais (a parte mais tipicamente burguesa pela sua origem, residência e formação) e caracteriza o gosto burguês em oposição a todos os outros gostos das outras fracções, em particular, ao gosto intelectual e ao gosto dos grandes comerciantes (uma mescla de gosto popular e de gosto médio). A partir da análise dos dados, Bourdieu considera provado que o volume e a estrutura do capital constituem o princípio da divisão das práticas e das preferências. A partir desta afirmação, o seu objectivo é o de compreender as razões da relação entre fracções relativamente mais ricas em capital cultural e mais pobres em capital económico, e a forma mais ascética das suas disposições estéticas e práticas culturais, ao mesmo tempo legítimas e menos onerosas do ponto de vista económico, como a visita a museus (que depende apenas do capital cultural), a marcha ou o alpinismo. O museu é um espaço de culto de obras excluídas de apropriação privada; ao contrário, as lojas e galerias são espaços onde os objectos, para além de poderem ser contemplados, podem ser adquiridos.

Apropriar-se de uma obra de arte é afirmar-se como o detentor exclusivo do objecto e com um gosto verdadeiro em relação a ele. O consumo da obra de arte é uma entre várias práticas distintivas, como o culto pela natureza: a apropriação da natureza, de animais, de plantas e de paisagens supõe cultura, e é vista como privilégio de pessoas com raízes antigas. Nesta perspectiva, a apropriação de um castelo, em si sinal de posse de capital económico, exige a apropriação dos signos que lhe são inerentes para ser completa, porque isso representa a apropriação da arte de viver como um aristocrata. Por esse motivo, é preciso garantir a posse de todas as propriedades dotadas do mais alto valor distintivo, que se acumulam, apenas, no decurso do tempo, pois são aquelas que melhor testemunham a qualidade da apropriação, logo, a qualidade do proprietário.

Por aí se explica a importância da busca da distinção em todas as práticas que demandam dispêndio puro e tempo, recurso precioso e raro. No entender de Bourdieu, a aquisição de obras 
de arte, testemunha objectivada do gosto pessoal, é a que melhor consagra a incorporação dos signos distintivos e dos símbolos do poder sob a forma de distinção natural e de autoridade pessoal e cultural.

Relativamente a outras fracções menos poderosas das classes dominantes, como intelectuais e artistas, a estratégia de afirmação da personalidade de proprietário recorre à singularidade do modo de apropriação, através da valorização como obra de arte, de objectos insignificantes ou que já deixaram de ser considerados obras de arte, numa estratégia de distinção que resulta da transformação desses objectos vulgares, através de uma maneira diferenciada de os consumir. $\mathrm{O}$ antagonismo entre os estilos de vida correspondentes a pólos opostos do campo da classe dominante é muito nítido: a oposição entre os professores e os patrões evoca a separação entre duas culturas, estilos próprios das práticas culturais, filosofias sociais e visões de mundo. Para o Autor, a melhor maneira de demonstrar a inclusão das escolhas estéticas no conjunto de escolhas éticas constitutivas do estilo de vida, recorre à oposição entre a aristocracia ascética dos professores e funcionários públicos - lazeres mais baratos e mais austeros, práticas culturais sérias e, até certo ponto, severas - e o gosto de luxo dos membros das profissões liberais - consumos mais onerosos e de maior prestígio. Estes, geralmente incapazes de reinvestir no campo económico os benefícios resultantes do capital cultural que possuem, encontram na prática de desportos e jogos chiques apenas as satisfações intrínsecas que lhes proporcionam, as convivências que lhes permitam cultivar relações e acumular a reputação de honradez, tão fundamental ao exercício das suas profissões.

Enquanto os segundos não têm os gostos proporcionais aos seus meios, os primeiros quase nunca têm os meios necessários para concretizar os seus gostos; daí a única saída para professores e artistas reside na substituição do «antigo» pelo «rústico»: a décalage entre capital cultural e capital económico é uma das razões da propensão deste grupo à contestação de uma ordem social que não valoriza, adequadamente, o capital escolar. Pelo contrário, a venda de produtos culturais pelos profissionais liberais, resulta em acumulação de capital económico e confunde-se com capital simbólico, pela aquisição da reputação de competência e de uma imagem de respeitabilidade e de honradez; isso os torna mais solidários com a ordem estabelecida. 
A oposição entre «gostos intelectuais» e «gostos burgueses» não se manifesta apenas em relação a obras de arte; reflecte-se, igualmente, em duas visões de mundo, duas filosofias de vida e seus respectivos símbolos estéticos e éticos. Enquanto as fracções intelectuais se inclinam para a contestação simbólica da realidade social e das representações burguesas, os burgueses esperam dos seus artistas símbolos de distinção que funcionem, simultaneamente, como instrumentos de negação da realidade social e de reforço da certeza em si próprios. A lógica do campo de produção artística de vanguarda funciona através de sucessivas oposições, definindo-se de maneira quase negativa como o somatório das negações de todos os gostos socialmente reconhecidos, como o «gosto médio» dos grandes comerciantes, o «gosto de luxo» tipicamente «burguês» e o «gosto pedante» dos professores, este último entendido como apenas uma variante daquele. Esta lógica leva os artistas a recuperar algumas das referências típicas do "gosto popular», num desafio que se reflecte, igualmente, no seu estilo de vida, distinto de todos os outros grupos, e supõe um património cultural também distinto, do qual se destaca a disponibilidade de tempo livre.

As diferenças entre gerações (e a potencialidade dos conflitos inter-geracionais) são tanto maiores quanto mais importantes hajam sido as mudanças ocorridas na definição dos postos ou das maneiras institucionalizadas de a eles aceder, bem como as variações do peso relativo dos distintos modos de acesso relacionados com as transformações do sistema escolar (como a extensão da escolaridade) e as relações deste com o aparelho produtivo. Por seu lado, as transformações na economia, produziram transformações nas relações numéricas e hierárquicas entre as funções de enquadramento e de direcção, e reflectiram-se também na desordem do sistema de probabilidades oferecidas aos produtos de diferentes tipos de formação, do autodidatismo aos cursos das grandes escolas. O Autor reconhece que ainda são as diferenças de origem social e escolar que determinam as diferenças significativas entre indivíduos que, num dado momento, ocupam posições formalmente idênticas: nisso reside o princípio das respostas diferentes que uns e outros podem dar às mudanças resultantes das transformações económicas. A criação de um grande número de «novas posições» prometendo benefícios no mínimo equivalentes aos das «posições estabelecidas», embora não oferecendo as mesmas garantias de segurança, tende a desordenar o sistema de probabilidades diferenciais de benefícios: 
na fase em que elas oferecem mais riscos, mas também mais benefícios, mostram tendências para posições arriscadas e possuem as relações e as informações necessárias para as realizar com sucesso.

A nova burguesia, constituída por pessoas que chegam mais jovens a posições de poder e que são, geralmente, portadoras de diplomas universitários, caracteriza-se em oposição à velha burguesia tradicional: eles trabalham em empresas mais importantes e mais modernas e adoptam um estilo de vida também mais moderno, opondo-se, igualmente, ao dos profissionais liberais - também moderno, mas mais cosmopolita, combinando luxo e cultura de forma diferente - devido ao seu papel na vida económica e às ligações internacionais da sua actividade profissional. Tanto a luta de classificações, que ocorre nas empresas e que visa subordinar a produção à publicidade e a engenharia ao marketing, como a luta no seio da fracção dirigente da classe dominante, são inseparáveis de conflitos de valores relacionados com visões de mundo e artes de viver, porque não apenas envolvem interesses de categorias, mas também de carreiras escolares e profissionais e, através delas, engajamentos sociais diferentes e, portanto, diferenças de habitus.

Esta luta permanente resulta de as transformações de postos (e dos seus ocupantes) serem acompanhadas, necessariamente, de todo um trabalho simbólico visando o reconhecimento nas representações, opondo os defensores de um novo sistema de classificação aos que permanecem vinculados ao antigo. No centro destas lutas simbólicas encontra-se o gosto, pois os investimentos em matéria de cultura não são apenas económicos, mas também psicológicos. É a nova burguesia que assume a iniciativa da conversão ética exigida pela nova economia, fundando uma nova lógica para substituir a lógica da moral ascética da produção e da acumulação, para servir uma economia com uma outra visão de mundo social, no qual as pessoas são avaliadas pelo padrão de consumo relacionado com o 860 seu estilo de vida, assim como pelas suas capacidades de produção. Os porta-vozes da nova arte de viver consumista procuram, principalmente junto das mulheres - consideradas pelo Autor «sujeitos e objectos privilegiados dos actos de consumo» - e recorrendo a uma persuasão impositiva, passar a mensagem de «indignidade moral» relacionada com a percepção de não estar à altura dos inumeráveis deveres de consumidor impostos pelo estilo de vida.

O estilo de vida da nova vanguarda ética exprime a estrutura do património que está na base do seu poder e das suas condições de 
vida. A nova concepção das empresas - no âmbito das mudanças provocadas pela unificação não apenas económica, mas também de mercados - , particularmente as multinacionais, desloca os seus executivos e quadros de uma relação com o local, com o espaço geográfico, projectando-os numa outra hierarquia nacional ou internacional, desconectada das interações locais e do universo das representações nos quais se construíram as relações de prestígio e de notoriedade dos «antigos» patrões das pequenas empresas. Os executivos e quadros das novas empresas são levados, por isso, a atribuírem aos seus títulos universitários, não só o prestígio de que gozam, mas também as visões modernistas do mundo social e económico, que repassam nas suas palestras. Esta ideia de que a legitimidade do seu poder resulta do capital escolar, está na base de profundas transformações não só na estrutura interna das fracções dominantes, mas também na estrutura das suas relações mútuas e destas com as fracções dominadas, e confere aos novos dirigentes da economia o sentimento de ter uma autoridade de direito intelectual sobre a conduta da sociedade.

\section{A escolha do necessário}

Retomando a ideia de que a classe social não se define, apenas, por uma posição nas relações de produção, mas também pelo habitus - enquanto produto dos condicionamentos impostos pelas condições de vida - que a ela está associado, importa recordar que a necessidade impõe um "gosto da necessidade», ou seja, uma forma de adaptação à necessidade e, através dela, a aceitação e a resignação perante a inevitabilidade da necessidade. Os sistemas de necessidades traduzem a coerência das escolhas de um habitus, e a incapacidade de gastar mais, ou de outra maneira é, segundo Bourdieu, a melhor comprovação da impossibilidade de reduzir propensões ao consumo às capacidades de apropriação ou o habitus às condições económicas pontuais. Se existe uma relação entre rendimento e consumo, é porque o «gosto» quase sempre resulta de condições económicas idênticas àquelas em que ele funciona, de maneira que se torna possível imputar ao rendimento uma eficácia causal que ele apenas exerce em associação com o habitus que a produziu. A eficácia do habitus é bem visível quando rendimentos iguais são relacionados com consumos muito distintos, 
apenas compreensíveis devido à intervenção de princípios de selecção distintos.

A submissão à necessidade, que condiciona as classes populares a uma estética pragmática e funcionalista, determina também as escolhas da vida do dia-a-dia e de uma arte de viver que impõe a exclusão das intenções propriamente estéticas, das actividades políticas e sindicais, em resultado da avaliação realista de condições e possibilidades. Nas escolhas do quotidiano destaca-se a preferência por produtos com o melhor custo/benefício: simples, duráveis, fáceis de manter, funcionais e resistentes, são as características dominantes.

A escolha do necessário, que se concretiza nas práticas das classes populares, funciona como se «gente simples e modesta» estivesse condenada a «gostos simples $e$ modestos». E as escolhas, que do ponto de vista das normas dominantes, aparecem como irracionais, são igualmente devidas ao «gosto da necessidade», agravado pelas consequências do reduzido capital cultural: falta de informação e de competências específicas. Outros exemplos demonstrativos de que a resignação e a necessidade se encontram na base deste tipo de gosto, são a negligência do cuidado com a saúde, o corpo e a beleza - principalmente por parte das mulheres das classes populares, duplamente dominadas - por serem consideradas práticas inúteis, desnecessárias ou «loucuras», por pessoas com baixos níveis de auto-estima.

As «chamadas à razão» do tipo «fulano não se enxerga», «sicrano está a sonhar muito alto», etc., baseiam-se neste princípio de conformidade - única norma explícita do gosto popular - e se por um lado visam encorajar escolhas adequadas às condições subjectivas de vida, por outro lado são castradoras, procurando desencorajar qualquer tendência de distinção pela identificação com outros grupos sociais, numa busca de construção de uma solidariedade de condição. Todo um conjunto de índices tende a mostrar, segundo Bourdieu, que as classes populares permanecem presas a uma moral muito conservadora no que respeita à sexualidade e à divisão sexual do trabalho. Antes de evocar um efeito de inércia cultural ou de atraso cultural, considera ser necessário questionar se a valorização da força física pelas classes populares - como dimensão fundamental da virilidade e de tudo o que a produz e mantém, como a comida e a bebida, os trabalhos e os exercícios de força - não estará relacionada com o facto de estas classes terem em comum a sua força 
de trabalho como único recurso, reduzida pelas leis da reprodução cultural e do mercado de trabalho, a simples força muscular.

A adaptação a uma posição dominada implica uma forma de aceitação dessa dominação. Não será muito difícil avaliar os efeitos de dependência da auto-estima dos signos de valor social - estatuto profissional e salário -, legitimados à partida pelas sanções do mercado escolar, conduzindo a sentimentos de incompetência, prejuízo ou indignidade cultural, forjados em oposição e como reconhecimento dos valores dominantes. $\mathrm{O}$ estilo de vida das classes populares caracteriza-se pela presença de substitutos de bens raros - do vestuário aos bens culturais, do mobiliário e habitação aos espetáculos de massa, culturais e desportivos, dos divertimentos pré-fabricados aos super-heróis -, sinalizando a destituição prevalecente.

Um aspecto que tem sido mascarado na crítica endereçada à cultura de massas, é que não é apenas no campo musical e no campo desportivo que as pessoas comuns são reduzidas à posição de fãs, que não é mais do que uma compensação ilusória da destituição em favor dos entendidos. A relação com os produtos culturais de massa reproduz, reactiva e reforça a relação social da desapropriação: na fábrica como na escola que ensina o respeito por saberes inúteis e estabelece relações investidas de autoridade «natural» da razão científica e pedagógica, os trabalhadores deparam com a cultura legítima como um princípio de ordem que não tem necessidade de demonstrar a sua utilidade prática para ser justificada. O sistema de ensino, que é um sistema de classificação objectivado, que reproduz hierarquias sociais com as clivagens correspondentes aos estratos sociais, transforma classificações sociais em classificações escolares e estabelece hierarquias totais, usadas para identificar o valor social e o valor pessoal, as dignidades escolares e a dignidade humana. A cultura é uma das componentes fundamentais do que faz um ser humano realizar-se na sua definição dominante, de forma que a sua privação é percebida como uma mutilação essencial que atinge a identidade e a dignidade da pessoa, (auto)condenando-a ao silêncio em público. A ideologia carismática, que imputa à pessoa, aos seus dons naturais ou aos seus méritos, a responsabilidade total do seu destino social, exerce os seus efeitos bem para além do sistema escolar, reflectindo-se em toda a vida social.

Segundo Bourdieu, esquecemos frequentemente que a lógica específica da dominação cultural pode coexistir, e coexiste não raras 
vezes, com a contestação mais radical da legitimidade política; mais, a tomada de consciência política é, muitas vezes, solidária com a luta pela reabilitação e restauração da auto-estima, alcançada a partir de uma reafirmação libertadora. A dignidade cultural implica uma forma de submissão aos valores dominantes e a alguns princípios sobre os quais a classe dominante funda a sua dominação, como o reconhecimento de hierarquias ligadas aos títulos escolares ou às capacidades que é suposto a escola garantir. Por este motivo, somos levados a pensar que a fracção mais consciente da classe trabalhadora está demasiado submetida aos valores e normas dominantes.

\section{Cesaltina Abreu}

(cf. supra, pp. 26-27) 